\title{
A importância dos serviços ecossistêmicos para o desenvolvimento econômico e o bem-estar social na percepção da população: o caso da Floresta Nacional de Carajás
}

\author{
Antônio Cordeiro de SANTANA ${ }^{1 *}$, Ádina Lima de SANTANA², Gilmara Maureline Teles da Silva de \\ OLIVEIRA $^{1}$, Ádamo Lima de SANTANA ${ }^{3}$, Javan Lobato QUARESMA ${ }^{4}$
}

\author{
${ }^{1}$ Instituto Socioambiental e dos Recursos Hídricos, Universidade Federal Rural de Amazônia, Belém, PA, Brasil. \\ ${ }^{2}$ Faculdade de Engenharia de Alimentos, Universidade Estadual de Campinas, Campinas, SP, Brasil. \\ ${ }^{3}$ Corporate R\&D Headquarters, Fuji Electric, Tokyo, Japan. \\ ${ }^{4}$ Programa de Pós-Graduação em Gestão de Recursos Naturais e Desenvolvimento Local, Universidade Federal Rural da Amazônia, \\ Belém, PA, Brasil. \\ *E-mail: acsufra@gmail.com
}

Recebido em março/2018; Aceito em maio/2018.

RESUMO: O estudo avaliou a percepção da população da região de Carajás sobre a influência da exploração dos recursos naturais, envolvendo desmatamento e queimadas, urbanização, alteração no clima e preservação da Floresta Nacional de Carajás sobre a economia e o bem-estar da população local. Aplicou-se a análise multivariada para associar um conjunto amplo de variáveis na definição de indicadores representativos das dimensões ambiental e ecológica. Os resultados indicaram que mais de $80 \%$ das pessoas entrevistadas afirmaram ter conhecimento sobre a importância da Flona de Carajás para o desempenho das atividades econômicas e do bem-estar da população do seu entorno. Os indicadores das dimensões ambiental e ecológica foram considerados, por mais de 52\% dos entrevistados, como de alta importância para compor o valor econômico total da Flona e contribuir para sua preservação e/ou gestão sustentável. Conclui-se que a população local percebe e qualifica os efeitos das mudanças causadas pela ação antrópica sobre os recursos naturais sobre o desempenho da economia e a qualidade de vida das pessoas.

Palavras-chave: economia ambiental, serviços ecossistêmicos, unidade de conservação, Floresta Amazônica.

\section{The importance of ecosystem services for economic development and social welfare in the population's perception: the case of the Carajás National Forest}

\begin{abstract}
This study evaluates the perceptions of the population residing in the region of Carajás with respect to the natural resource exploitation, deforestation and forest fires, urbanization, climate change and the preservation of the Carajás National Forest, considering the economy and welfare of local the population. Multivariate analysis was applied to associate a wide group of variables with the representative indicators in environmental and ecological dimensions. Interviews with local people indicate that more than $80 \%$ of all interviewed are aware of the importance of the Carajás Flona for the development of economic activities and for the population's welfare in their surroundings. Indicators of environmental and ecological dimensions were regarded by more than $52 \%$ of interviewees as being of great importance to the composition the total economic value of Flona and to contribute to preservation or sustainable management. We conclude that the local population adequately perceived and qualified the effects of the changes caused by the anthropic action on the natural resources with respect to the development of economy and the quality of life of the people.
\end{abstract}

Keywords: environmental economics, ecosystem services, conservation unit, Amazon Forest.

\section{INTRODUÇÃO}

Na Floresta Nacional de Carajás (Flona de Carajás), estado do Pará, existe uma área de vegetação de savana metalófita, denominada de canga, composta de gramíneas, espécies arbustivas e rupestres, capão de floresta, espécies de áreas inundáveis, jaborandi (Pilocarpus microphyllus Stapfex Wardleworth), buriti (Mauritia flexuosa Mart.) e espécies raras e/ou endêmicas como a flor de Carajás (Ipomoea cavalcantei $\mathrm{D}$. Austin). A canga ocupa áreas nos platôs, onde a rocha com o minério de ferro aflora, que define os divisores de água e abriga um ecossistema diferenciado do bioma Amazônia com 4\% a 5\% dos 411.949 ha da Flona de Carajás (CAMPOS; CASTILHO, 2012; SANTANA, 2014). Nesta área, além da extração de minérios e da conservação da floresta, ocorre também a coleta dos ramos do jaborandi para fins comerciais e a prática do turismo ecológico de contemplação para que os visitantes cotejem o ambiente de contraste entre a canga e a floresta densa, no coração do bioma Amazônia. Ocorre que o ativo natural que cobre o solo da Flona de Carajás é retirado e indenizado para viabilizar a extração do minério de ferro pela empresa Vale do Rio Doce (VALE).

Em função da presença de espécies desconhecidas, raras e/ou endêmicas e que não têm preço de mercado, os métodos de valoração desses recursos naturais tornam-se mais complexos. Neste caso, além dos aspectos puramente econômicos, deve-se incorporar as componentes sociais e ambientais. Portanto, a valoração dos ativos naturais difere substancialmente da análise privada dos ativos, uma vez que não podem ser avaliados apenas como insumos, mas também 
como ativos que geram serviços ecossistêmicos ou serviços ambientais (COSTANZA et al., 1997; SANTANA et al., 2017a).

Nesse sentido, em qualquer análise de valoração desses serviços, é relevante conhecer a percepção da população beneficiada sobre a contribuição da natureza para a atividade econômica e o bem-estar da sociedade. A partir deste conhecimento, pode-se aproximar o valor dos serviços ecossistêmicos à realidade dos mercados de produtos e de serviços, por meio da sua valoração e inclusão dos resultados no patrimônio do imóvel rural e na contabilidade nacional. Assim, este estudo contribui para ampliar o conhecimento sobre os benefícios produzidos pelos serviços ecossistêmicos para a qualidade de vida da humanidade e para o aprimoramento dos métodos de valoração contingente e para a gestão dos recursos naturais.

$\mathrm{Na}$ Flona de Carajás, quando a área a ser minerada pela Vale é coberta com espécies vegetais que não tem valor de mercado, espécies raras e/ou endêmicas, a metodologia de avaliação deve considerar além do valor de uso direto e indireto do recurso, o valor de opção e o valor de existência dessas espécies. Portanto, um dos desafios deste trabalho é gerar informação monetárias sobre a importância das dimensões ambiental e ecológica dos serviços ecossistêmicos produzidos pela Flona de Carajás para a economia local e para o bem-estar humano, o que representa uma contribuição metodológica e científica para a valoração de ativos naturais. Assim, a questão central a ser respondida é como determinar sua participação no valor econômico total (valor de uso direto e indireto, valor de opção e valor de existência) da vegetação florestal e/ou da área de canga a ser minerada. Assim, como contemplar os atributos econômicos, sociodemográficos, ambientais e ecológicos desses serviços nos modelos de análise benefício-custo e de avaliação contingente, especificados pelas equações de disposição a pagar e disposição a receber?

As dimensões ambiental e ecológica são definidas por um conjunto de variáveis que representam seus efeitos e são, geralmente, definidas na forma qualitativa e, algumas delas, no formato zero e um (SANTANA, 2014). Esta prática tende a gerar problemas econométricos, por causa da alta multicolinearidade entre as variáveis explicativas, o que torna difícil isolar a contribuição de cada variável sobre o valor do ativo natural. Para superar esta questão, observada em quase todos os textos consultados, é necessário construir indicadores para representar o efeito conjunto das variáveis associadas a tais dimensões. Com isto, pode-se contribuir para corrigir as deficiências que, no geral, estão associadas às estimativas do valor por meio da disposição a pagar e da disposição a receber (HANEMANN, 1994; LOOMIS et al., 2000; SANTANA, 2014; SANTANA, 2015; SANTANA et al., 2017a).

O objetivo do trabalho foi gerar informação, com base na percepção da população da região de Carajás, sobre a magnitude e importância dos efeitos de mudanças climáticas e do uso dos recursos naturais na qualidade de vida das pessoas e, em função disso, construir indicadores para representar seus efeitos sobre a disposição a pagar e a disposição a receber. Com isso, espera-se ainda validar o método integrado de avaliação contingente a ser utilizado na estimação do valor econômico total de ativos naturais da Flona de Carajás para fins de preservação e/ou de utilização, contemplando espécies raras, endêmicas e a importância dos serviços ecossistêmicos. 2. REFERENCIAL TEÓRICO
Os produtos e serviços ecossistêmicos resultam de complexas relações entre os seres vivos e não vivos, que determinam a capacidade da natureza de fornecer qualidade de vida e comodidade para todos (COSTANZA; DALY, 1992; COSTANZA et al., 1997; WALLACE, 2007; SANTANA et al., 2017b). Portanto, estes serviços contribuem para o bemestar humano e podem ser agrupados em quatro categorias, conforme Santana et al. (2016): (i) serviço de provisão, como alimentos e fibras, madeira, sementes, recursos genéticos, produtos bioquímicos, medicinais, farmacêuticos, ornamentais e água; (ii) serviço de regulação ambiental, como o controle do clima, intempéries, ventos, polinização, doenças e pragas, purificação da água e do ar e proteção do solo; (iii) o serviço cultural, como valores culturais e sociais, religiosos e espirituais, conhecimento da fauna e flora, valores paisagísticos, recreação e turismo; e (iv) serviço de suporte, que define a produção de outros serviços, como a formação e retenção do solo, fotossíntese, ciclagem de nutrientes, atividade biológica do solo, ciclagem da água e manutenção da dinâmica do habitat.

Os ecossistemas da Flona de Carajás produzem todos esses serviços e alguns de seus componentes como madeira, frutas, água, produtos medicinais, espécies raras e ameaçadas, paisagens, minérios e condições climáticas, além continuam sendo percebidos e consumidos pela população local ao longo dos últimos 40 anos. Ao mesmo tempo, os estoques de recursos naturais da área do entorno da Flona continuam sendo utilizados de forma insustentável e/ou destruídos por meio do desmatamento e queimadas para a implantação de agricultura e/ou pecuária, abertura de estradas, extração de minérios e de madeira, urbanização, poluição dos rios e igarapés (SANTANA et al., 2011). Mesmo com estes cenários antagônicos de ambiente preservado e destruído, a sociedade ainda não consegue estimar a magnitude do valor da perda de bem-estar social causado pela diminuição dos produtos e serviços produzidos por este ativo natural (SANTANA et al., 2017a,b).

Com efeito, a garantia desse fluxo de produtos e serviços depende do conhecimento por parte da população sobre a contribuição que geram para o desenvolvimento econômico e para a melhoria da qualidade de vida das pessoas (FISHER et al., 1972; HANEMANN, 1994; SUTTON; COSTANZA, 2002; TURNER et al., 2003; LIU et al., 2010; GROOT et al., 2012; COSTANZA et al., 2014; SANTANA et al., 2015; 2016). Assim, é defendido que para que a proteção e/ou exploração sustentável dos ativos naturais seja viabilizada, com vistas a alcançar e manter uma situação de máximo bemestar social, a partir da combinação entre capital natural, capital humano e capital manufaturado, é necessário atribuir valor econômico com base no custo de oportunidade (FISHER et al., 1972; HOEHN; RANDALL, 1989; CARSON; LOUVIERE, 2011; CARSON, 2012; COSTANZA et al., 2014; BENTES et al., 2014; ROSA et al., 2016; SANTANA et al., 2015; 2016). Esta informação é um dos elementos a ser considerado na formulação de políticas e decisões com vistas a orientar a alocação dos recursos naturais.

Neste estudo, identificou-se o grau de percepção da população local sobre os impactos da exploração dos recursos naturais, desmatamento e queimadas, alterações do clima e do ecossistema da Flona de Carajás e área do entorno. Em seguida, estabeleceu-se o vínculo da degradação ambiental com a perda do bem-estar social e o valor da compensação equivalente a esta perda na qualidade de vida. Este vínculo é 
fundamental para o reconhecimento de que os ativos naturais compõem parcela significativa do valor econômico total da Terra (COSTANZA et al., 1997) e, desta forma, devem ser conservados e/ou explorados de forma sustentável para assegurar o desenvolvimento industrial e o bem-estar da população (BARAL et al., 2008; COSTANZA et al., 2014; SANTANA, 2015; ROSA et al., 2016; SANTANA et al., 2016; 2017b).

Portanto, a especificidade das espécies vegetal e animal, desconhecidas, raras e/ou endêmicas da Flona de Carajás e cujo valor de uso e/ou de não uso ainda é uma incógnita, pode ser contemplada nos métodos integrados de avaliação contingente (LOOMIS et al., 1996; BARAL et al., 2008; ADAMS et al., 2008; GROOT et al., 2012; COSTANZA et al. 2014; SANTANA, 2014; SANTANA et al., 2016; 2017a). Com efeito, foi possível identificar e avaliar o efeito de um conjunto de variáveis ambientais e ecológicas na construção de indicadores para representar a contribuição destas dimensões no valor econômico total dos ativos naturais. Assim, estes indicadores tornam mais adequada a especificação dos modelos econométricos de avaliação contingente e tornam a estimação dos parâmetros das regressões incluídas em tais modelos adequada e os resultados estatisticamente significativos.

\section{MATERIAL E MÉTODOS}

A área de estudo abrangeu um raio de $150 \mathrm{~km}$ da área de influência direta e indireta da Flona de Carajás, contemplando a população dos municípios de Parauapebas, Canaã dos Carajás e Curionópolis, no estado do Pará. Os dados foram obtidos a partir da aplicação de um questionário com perguntas fechadas e abertas durante os meses de maio e junho de 2014, abrangendo variáveis definidoras das dimensões sociodemográficas, ambientais, socioeconômicas e sobre a canga e seu potencial uso. Para este estudo específico, no entanto, apenas as variáveis das duas dimensões seguintes foram utilizadas:

a) Os aspectos ambientais definidores das condições do meio ambiente da área de pesquisa: variação na distribuição das chuvas (intensidade e periodicidade), conservação da floresta, utilização de queimadas, utilização de agrotóxico, utilização de técnicas agronômicas para o desenvolvimento sustentável, desmatamento, caça e pesca predatória, potencialidade de uso sustentável e/ou preservação da flora e da fauna, qualidade da água dos rios e nascentes, belezas cênicas naturais. Estes aspectos foram contemplados nas seguintes 14 variáveis utilizadas no questionário: A1. Aumento na irregularidade das chuvas; A2. Aumento das cheias dos rios e das inundações; A3. Preservação da biodiversidade (fauna e flora); A4. Conscientização ambiental da população; A5. Poluição das águas dos rios e cursos d'água; A6. Diminuição da quantidade de peixe dos rios; A7. Diminuição de queimadas no preparo de roças; A8 Diminuição de queimadas em pastagens; A9. Conflitos pela posse e uso da terra; A10. Chegada de pessoas de outras áreas para o local; A11. Deslocamento de pessoas para outras áreas; A12. Redução da coleta de frutas, castanhas e plantas; A13. Redução na extração de madeira e lenha; A14. Aumento de turistas para ver as belezas naturais. b) As características ambientais e as potencialidades socioeconômicas dos recursos disponíveis na Flona de Carajás: espécies florestais de valor comercial, animais selvagens para caça, espécies raras e/ou endêmicas, produtos florestais madeireiros e não madeireiros, recursos minerais, presença de nascentes, cachoeiras e paisagens com potencial para recreação e/ou turismo ecológico e de contemplação. Estas características foram contempladas nas nove seguintes variáveis incluídas no questionário: B1. Floresta é rica em madeira de valor comercial; B2. Produção de frutas, sementes e óleos vegetais; B3. Animais para a caça; B4. Terra com aptidão para pastagem; B5. Terra com aptidão para agricultura; B6. Nascentes e rios de água potável; B7. Áreas com belezas naturais para turístico; B8. Espécies desconhecidas, raras ou endêmicas; B9. Bacias hidrográficas reguladoras do clima.

A amostra da população foi definida pelo número de famílias residentes na área de estudo, distribuídas em vinte vilas do entorno da Flona de Carajás, considerando os atributos de proximidade, conhecimento, tempo de moradia e convivência com as dinâmicas do desenvolvimento local. A amostra incluiu os diversos perfis de entrevistados de áreas urbanas e rurais: empresários, professores de educação ambiental, professores de biologia, professores de história, professores de exatas, especialistas em gestão ambiental, agentes de saúde, produtores rurais, trabalhadores do Movimento dos Trabalhadores Rurais Sem Terra (MST), representantes de associação, trabalhadores de empresas, comerciantes, técnicos das secretarias de meio ambiente, de desenvolvimento rural, da extensão rural, agência de turismo, estudantes, entre outros. Sobre o conhecimento da canga, conforme Santana (2014), pelo menos 80\% deles declararam que conhecem o ecossistema da canga e seus efeitos sobre o bem-estar humano e os $20 \%$ restantes, ao verem fotos da vegetação da canga, conseguiram espontaneamente associar a canga com a vegetação de áreas de cerrado.

$\mathrm{O}$ tamanho mínimo representativo da amostra probabilística com nível de confiança de $95 \%$ e erro amostral de $5 \%$ foi de 369 entrevistados da população de 8.956 famílias (SANTANA, 2014; SANTANA et al., 2017a,b). O número total de questionários válidos deste estudo foi de 442, número $19,8 \%$ superior, o que amplia a margem de segurança da pesquisa.

A abordagem dos entrevistados foi realizada por sete profissionais com experiência em pesquisa de campo, que receberam orientação adicional para enfatizar 0 esclarecimento dos entrevistados sobre o objetivo da pesquisa e sobre as características dos ecossistemas da floresta e da savana metalófita da Flona de Carajás, por meio da apresentação de fotos com os diversos tipos de vegetação e suas potencialidades. Os dados sobre as variáveis definidoras das duas dimensões apresentadas foram submetidos à análise multivariada para a construção de indicadores que as representem de forma adequada.

As variáveis que explicam as dimensões ambiental e ecológica foram submetidas à análise fatorial para definir os fatores em sintonia com a multifuncionalidade dos produtos e serviços ecossistêmicos da Flona de Carajás, e viabilizar a construção dos indicadores das dimensões ambiental e ecológica. Estes indicadores, conforme Santana (2014) e 
Santana et al. (2016), entram como variáveis explanatórias nas equações de disposição a pagar e disposição a receber da avaliação contingente. Assim, evitam-se os problemas de multicolinearidade causados pela utilização de grande número de variáveis qualitativas nas equações, como evidenciado nos trabalhos de Adams et al. (2008), Baral et al. (2008) e Veronesi et al. (2014).

\subsection{Método da análise fatorial}

A Análise Fatorial (AF) foi utilizada para identificar e caracterizar fatores latentes ou constructos subjacentes à análise de dados, que fundamentam as relações das variáveis observadas. A AF é compreendida como uma ferramenta que permite resumir as informações do fenômeno estudado em um número de fatores substancialmente menor do que o número total de variáveis total sem uma perda significativa de informação (JOHNSON; WICHERN, 2007). Assim, a AF foi utilizada para descreveras relações de covariância entre as variáveis que definem as dimensões ambiental e ecológica dos ecossistemas da Flona de Carajás e de seu entorno no desenvolvimento local e na qualidade de vida da população, para reduzi-las a poucos fatores e, a partir destes construir os dois indicadores que representam seus comportamentos.

No modelo de AF, assume-se que cada variável observada é uma combinação linear dos fatores latentes extraídos, tal que cada variável aleatória $i$ pertence a uma população homogênea com média $\mu_{\mathrm{i}}$ (DILLON; GOLDSTEIN, 1984; SANTANA, 2007; SANTANA et al., 2014).

$y i-\mu i=\psi f i+e i \quad(i=1,2, \ldots, N) \quad($ Equação 1$)$

em que: $\psi$ é a matriz de pesos fatoriais ( $\mathrm{x} \mathrm{q);} ; f_{i}$ é o vetor de fatores latentes $(q \times 1) ; e_{i}$ é o vetor de erros aleatórios $(p \times 1)$. Assume-se a independência entre $f_{i}$ e $e_{i}$, com $V\left(f_{i}\right)=\Sigma_{f}$ e $V\left(e_{i}\right)=\Sigma_{e}$ dando origem a matriz de covariância de $y_{i}$, dada por $V\left(y_{i}\right)=\psi \Sigma_{f} \psi^{\prime}+\Sigma_{e}$ (DILLON; GOLDSTEIN, 1984; SANTANA, 2007). O primeiro termo do lado direito representa a parcela da covariância atribuída aos fatores comuns e o segundo termo a covariância atribuída ao erro. Assim, a comunalidade, ou parcela da variância comum presente na variável é dada pelos elementos da diagonal principal de $\psi \Sigma_{f} \psi^{\prime}$, enquanto que a variância específica do erro é dada pelos elementos da diagonal principal de $\Sigma_{e}$.

Os erros são não correlacionados aos fatores latentes, ou seja, $\operatorname{Cov}\left(e_{i} f_{i}^{\prime}\right)=E\left(e_{i} f_{i}^{\prime}\right)=0$, de modo que as inter-relações entre as $p$ variáveis são totalmente explicadas pelos $q$ fatores latentes. Este resultado significa que os vetores $e_{i}$ e $f_{i}$ representam duas fontes de variação distintas e, portanto, sem qualquer relacionamento entre si. Assim, com $\Sigma \square_{f}=I_{q}$, o modelo reduz-se a $V\left(y_{i}\right)=\psi \psi^{\prime}+\Sigma_{e}$.

$\mathrm{A}$ adequação da amostra ao método de AF foi feita pelos testes de Kaiser-Meyer-Oklin (KMO) e de Bartlett (JOHNSON; WICHERN, 2007; HAIR JR et al., 2009). Estes testes são procedimentos estatísticos que permitem aferir a qualidade das correlações entre as variáveis de forma a seguir com a AF (SANTANA, 2014). Aplicou-se também, nos dois modelos, o método da rotação ortogonal varimax porque atinge um padrão teoricamente mais significativo e mais simples de interpretar os fatores.

Por fim, o número de fatores extraídos para descrever os dados foi determinado pelo método de Kaiser, que recomenda a escolha daqueles cuja variância explicada é superior a 1 (DILLON; GOLDSTEIN, 1984; JOHNSON; WICHERN,
2007). Além disso, o número de fatores extraídos deve explicar pelo menos $60 \%$ da variância total dos dados (DILLON; GOLDSTEIN, 1984; SANTANA et al., 2007). Outra condição necessária para a inclusão de variáveis no modelo de AF é que apresentem comunalidade igual ou superior a 0,50 (HAIR JR et al., 2009; FERREIRA et al., 2016), ou seja, pelo menos 50\% de suas variâncias sejam explicadas pelos fatores comuns extraídos.

Os indicadores que representam a percepção por parte dos entrevistados sobre a mudança nas chuvas e conservação do meio ambiente (ICA) e do potencial econômico e ecológico de uso da Flona de Carajás e seu entorno (IPEE), além da opção de realizar a exploração mineral. Tais indicadores foram definidos, conforme Santana (2007) como uma combinação linear dos escores fatoriais e a proporção da variância explicada por cada fator em relação à variância comum. A expressão matemática é dada por:

$$
\begin{gathered}
I_{i k}=\sum_{j=1}^{q}\left(\frac{\lambda_{j}}{\sum \lambda} F P_{i j k}\right) ;(i=1, \ldots, N) e(k=I C A, I P E E) \\
\text { (Equação } 2)
\end{gathered}
$$

em que: $\lambda$ é a variância explicada por cada fator e $\Sigma \lambda$ é a soma total da variância explicada pelo conjunto de fatores comuns. O escore fatorial foi padronizado $(F P)$ para que os valores sejam todos positivos. A fórmula utilizada foi a seguinte:

$F P_{i}=\left(\frac{F_{i}-F_{\min }}{F_{\max }-F_{\min }}\right) ;(i=1, \ldots, N)$

(Equação 3)

em que: $F_{\text {máx }}$ e $F_{\text {min }}$ são os valores máximo e mínimo observados para os escores fatoriais associados às pessoas entrevistadas. Para facilitar a interpretação dos resultados, foram estabelecidos os seguintes intervalos de variação do $I C A$ (e do $I P E E$ ): valores do $I C A$ (e do $I P E E$ ) igual ou superior a 0,80 são considerados muito altos; valores entre 0,6 e 0,79 são considerados altos; valores situados entre 0,40 e 0,59 são intermediários; e valores inferiores a 0,40 são considerados baixos.Com base nestes resultados, pode-se avaliar o grau de compreensão dos entrevistados sobre as questões ambientais e ecológicas e a avaliação potencial da sociedade tomaras decisões de preservar e/ou explorar os recursos naturais dos ecossistemas da Flona de Carajás e de seu entorno.

\section{RESULTADOS}

A amostra contemplou $50,9 \%$ de entrevistados do sexo masculino e $49,1 \%$ do sexo feminino. Quanto à idade média do entrevistado, tem-se que $60,9 \%$ estavam com até 45 anos, $24,0 \%$ com 18 a 30 anos, 30,8\% com 45 a 65 anos e 8,4\% com mais de 65 anos. Entre estes, 2,8\% são analfabetos e 45,5\% estudaram até o ensino fundamental. No geral, $47,4 \%$ e $35,3 \%$ dos entrevistados, respectivamente com até 45 anos e com idade superior a 45 anos, têm o ensino médio completo. Com relação à renda, $63,6 \%$ dos entrevistados ganham até três salários mínimos por mês. Um percentual de $22,9 \%$ ganha entre três e cinco salários mínimos e 2,0\% ganham entre 10 e 25 salários mínimos por mês, incluindo todas as fontes de renda. Quanto ao tempo em que residem na área, tem-se que $75,1 \%$ moram na região há pelo menos 10 anos e $34,8 \%$ residem no local há mais de 20 anos.

\subsection{A dimensão ambiental}

Os fatores ambientais que influenciam os serviços ecossistêmicos e foram percebidos diretamente pelos entrevistados contemplam: mudanças climáticas (irregularidades na distribuição e intensidade das chuvas, enchentes, alagamentos e secas prolongadas); queimadas 
acidentais e aquelas utilizadas na preparação de roça e no manejo de pastagens; poluição dos rios e nascentes; biodiversidade (fauna e flora);caça e pesca; extrativismo de produtos florestais madeireiros e não madeireiro; extração de minérios e garimpo; conflitos pela posse e uso da terra; aspectos da migração de pessoas.

Com relação às mudanças observadas na distribuição das chuvas e seus efeitos, mais de $90 \%$ dos entrevistados declararam que a distribuição das chuvas vem mudando ao longo do tempo e se tornando cada vez mais acentuada (Figura 1). O período das chuvas diminuiu e a intensidade das chuvas passou a variar na direção dos extremos, com "fortes chuvas em curto espaço de tempo e com chuvas fracas e irregulares". Isto foi indicado por $43,4 \%$ dos entrevistados como sendo uma mudança de alta irregularidade no padrão das chuvas em relação aos últimos 10 a 20 anos. Os demais enquadraram tais mudanças na distribuição das chuvas como de moderada a baixa. Apenas 9,4\% não perceberam as mudanças, em função do pouco tempo na região, ou por não se preocuparem com a influência do clima nas atividades rurais e urbanas. A implicação desta variável, conforme Veronesi et al. (2014) e relato dos entrevistados tem implicação sistêmica porque a escassez prolongada das chuvas aumenta o risco das queimadas acidentais, compromete a produção e de produtividade das lavouras e pastagens, diminui o fluxo de água potável e compromete a criação de animais.
A segunda variável, que se traduz como reflexo da mudança na distribuição das chuvas e na temperatura foi evidenciada por meio das cheias dos rios e igarapés causando inundações nos centros urbanos, destruindo pontes e estradas vicinais e aumentando o risco de doenças. Cerca de $72,7 \%$ dos entrevistados perceberam que as cheias dos rios se tornaram mais frequentes e com maior gravidade, em função do desmatamento e do aumento rápido e desordenado da urbanização.

Observa-se que 69,3\% perceberam que houve mudanças quanto à preservação da fauna e da flora, porque os órgãos ambientais intensificaram a fiscalização e a Vale segue a legislação ambiental. Como consequência dessa ação de proteção da Flona de Carajás e do ensino de educação ambiental em algumas escolas, 76,5\% dos entrevistados informaram que houve aumento da conscientização ambiental, embora a prática ainda leve tempo para se tornar uma ação de parcela representativa da população. Não foi identificada a coleta regular e/ou seletiva do lixo doméstico produzido nas vilas e nas cidades. Foi declarada e constatada a ausência de saneamento básico nas vilas e nas cidades. Por outro lado, no que tange aos instrumentos de informação sobre as questões ambientais, muitas placas foram encontradas com alertas e orientações para os cuidados com os problemas ambientais. Contudo, os avisos desprovidos da execução efetiva dos projetos não estão produzindo mudanças significativas.

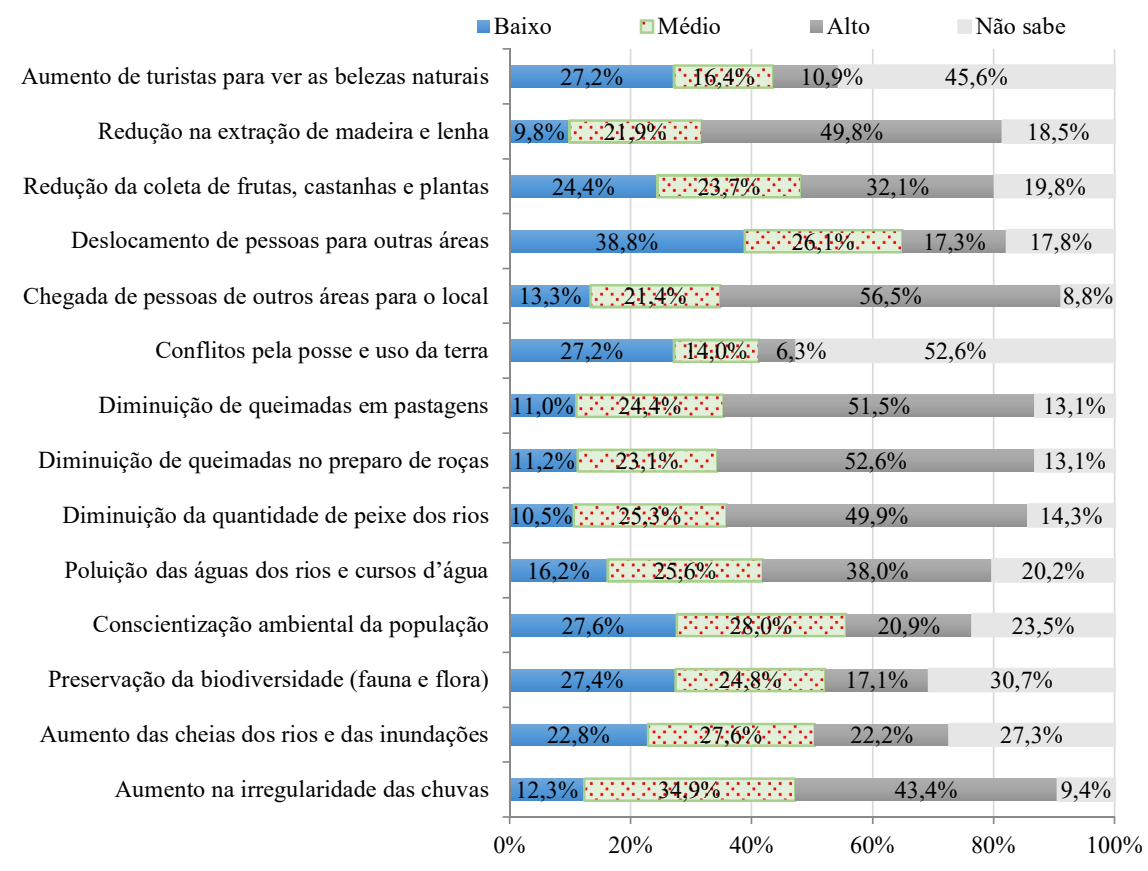

Figura 1. Características das mudanças ambientais e de uso sustentável dos ativos ambientais na área da pesquisa segundo perspectiva dos entrevistados, estado do Pará, 2014.Fonte: Dados da pesquisa.

Figure 1. Characteristics of environmental changes and of sustainable use of environmental actives in research area according to the perspectives of people interviewed, state of Pará, 2014.

Com efeito, 79,8\% dos entrevistados observaram que a poluição das águas dos rios aumentou e o exemplo de referência é atribuído ao rio Parauapebas, que "não tem mais peixes", assim como outros rios e igarapés cuja "captura de peixes está cada vez mais difícil". Em consequência dessa poluição e do aumento do esforço de pesca por parte de maior contingente de pessoas em determinados locais, 85,7\% revelaram que houve acentuada queda da pesca extrativa. Os reflexos destas externalidades foram observados no aumento de projetos de pesca em cativeiro e considerados como de intermediária a elevada magnitude pela maior parte dos entrevistados (Figura 1).

No que tange às queimadas de mata nativa para a formação de roças e para a implantação e/ou manejo de pastagens, $86,9 \%$ declararam que houve redução dessa prática, em função da intensidade da fiscalização por parte dos órgãos ambientais. Também diminuiu a incidência de incêndio natural e/ou acidental na área de savana, por causa da 
proibição da caça e da extração de produtos florestais da Flona de Carajás. As queimadas, além de emitirem grande quantidade de $\mathrm{CO}_{2}$, destroem a fauna e a flora e eliminam o valor econômico dos produtos e serviços produzidos pelos ecossistemas (SANTANA et al., 2011; SANTANA, 2015; SANTANA et al., 2017a,b). Este efeito ocorreu em toda a região do entorno da Flona de Carajás, daí a importância da sua preservação e/ou exploração das áreas liberadas pelo ICMBio mediante a compensação equivalente à perda de valor do bioma e do bem-estar da população.

Com relação aos conflitos pela posse e uso da terra, $47,4 \%$ informaram que houve forte diminuição ao longo do tempo na área rural (Figura 1). Onde este movimento ainda está em curso, a avaliação é que a intensidade das ações foi considerada baixa. Este é um ponto importante de avanço dos projetos de assentamento da reforma agrária e das políticas de transferência de renda, que estão contribuindo com a redução do uso do fogo pela agricultura familiar praticada nas áreas do entorno da Flona de Carajás. No extrativismo vegetal de produtos madeireiros e não madeireiros, mais de $80 \%$ dos entrevistados observaram que a diminuição foi de intermediária a alta, indicando a perda de importância dessa atividade, em função do aumento da fiscalização.

O fluxo de migrantes de outras regiões que chegam ao local ocorre em função das oportunidades de trabalho nas empresas que prestam serviços à Vale. Pelas características da atividade de extração de minérios, a ocupação da mão de obra de baixa qualificação tem vida curta, perdurando apenas na primeira fase da exploração. Depois, muita gente é dispensada e a migração segue o caminho inverso para os locais de origem ou para outras áreas do entorno da Flona de Carajás, ampliando as favelas na periferia das cidades e/ou criando novas vilas. No turismo, $54,4 \%$ dos entrevistados perceberam que houve aumento no fluxo de pessoas que visitam a região como turista, em busca das belezas cênicas que a Flona de Carajás e seu entorno oferece, como a fonte de "águas termais" no Garimpo das Pedras, produção de pedras semipreciosas, os balneários da Área de Proteção Ambiental do Gelado, a vegetação de savana contrastando com a floresta densa, cavernas, espécies raras e/ou endêmicas e os animais ameaçados de extinção do Parque Zoobotânico da Vale.

\subsection{A dimensão ecológica}

Avaliou-se a percepção dos entrevistados sobre o fluxo dos serviços ecossistêmicos da Flona de Carajás em termos do valor de uso, valor de opção e valor de existência.

No caso dos produtos e serviços de uso direto, ou serviços de provisão, mais de $80 \%$ dos entrevistados revelaram que a Flona de Carajás é rica em espécies de madeira com alto valor comercial (cedro, copaíba, cumaru, freijó, ipê, jacarandá, jatobá, piquiá, virola), frutas e óleos vegetais (abiu, bacaba, buriti, castanha-do-brasil, castanha de caju, cacau, copaíba, ingá), assim como animais para caça (aves, cutia, paca, porco do mato, tatu) e as belezas cênicas e relevos da área da Flona e de seu entorno (Figura 2). Observou-se, também, que as terras do entorno têm aptidão para o desenvolvimento de pastagens para a pecuária de corte e de leite e de lavouras temporárias e permanentes, uma vez que as áreas do entorno estão povoadas com agricultura e pecuária em diversos estágios de degradação, ou seja, o serviço de suporte do solo. Por último, os resultados da Figura 2 revelaram forte predominância das respostas indicando alto potencial econômico e ecológico da Flona de Carajás, o que estabelece uma relação direta do valor dessa unidade de conservação para o crescimento econômico e o bem-estar da população local.

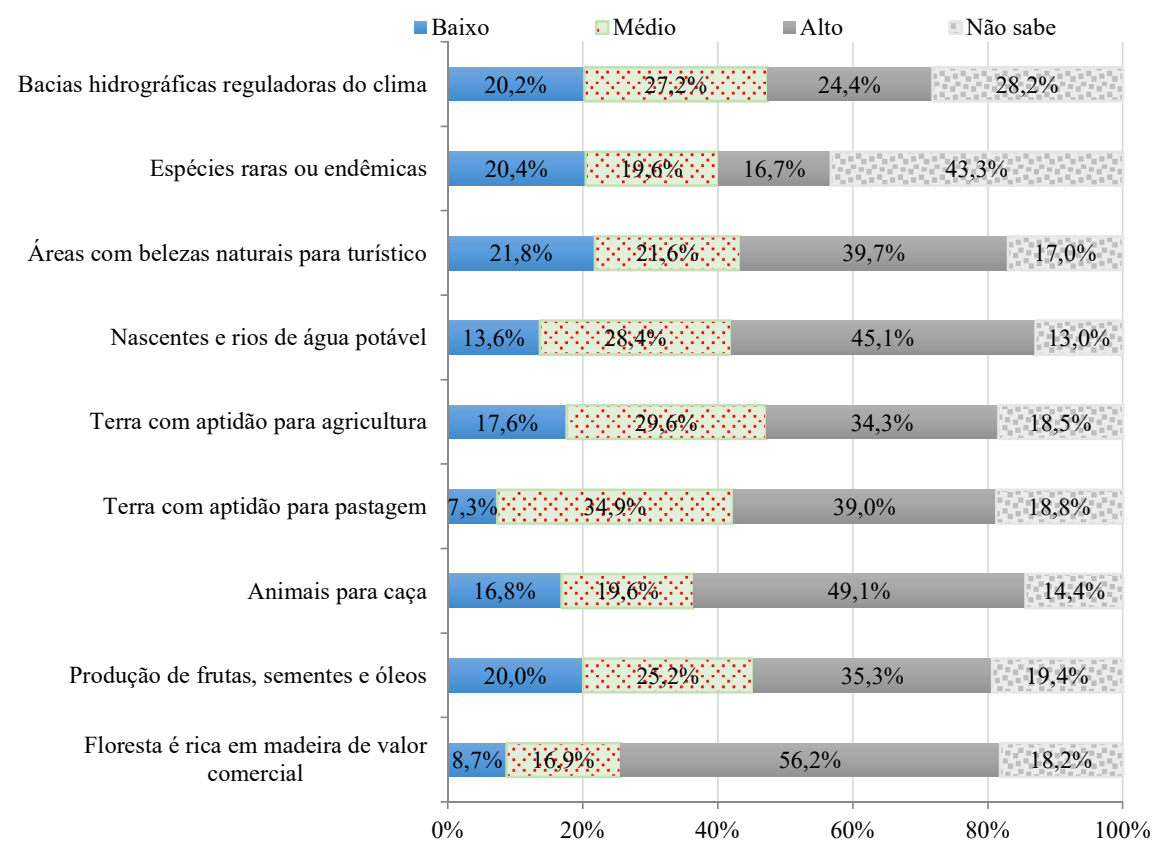

Figura 2. Potencial da Floresta Nacional de Carajás e de seu entorno em relação ao valor de uso e de não uso, estado do Pará, 2014. Figure 2. Potential of the Carajás National Forest and its surroundings with respect to the value of use and non-use estate of Pará, 2014.

Com relação aos serviços ambientais de uso indireto, envolvendo as funções culturais, mais de $87 \%$ dos entrevistados informaram que há muitas nascentes com água potável (Figura 2). No caso das belezas naturais como paisagens florísticas, cachoeiras e águas termais, que podem ser exploradas pelo turismo ecológico e de contemplação, $71,8 \%$ dos entrevistados declarou que elas existem e devem ser conservadas. As avaliações concentram-se na posição 
elevada, o que revela o reconhecimento do valor dos serviços ecossistêmicos da Flona de Carajás para o bem-estar humano.

As variáveis que refletem o valor de não uso dos recursos, em função de conhecimento genético e características de raridade e endemismo, encontram-se as espécies como o gavião real e outros animais ameaçados de extinção que vivem na Flona de Carajás. Como espécie endêmica foi citada a flor de Carajás. Esta variável apresentou o maior percentual de pessoas que não fez avaliação, dada a falta de informação.

Por fim, os resultados mostram dois aspectos fundamentais para a compreensão do valor econômico dos ecossistemas da Flona de Carajás. $\mathrm{O}$ primeiro se refere à percepção dos entrevistados sobre os efeitos das mudanças nas dimensões ambiental e ecológica produzidos pela ação antrópica, o grau de importância para o crescimento da economia local e para a qualidade de vida das pessoas. $\mathrm{O}$ segundo é que a inclusão de todas estas variáveis qualitativas (14 sobre a dimensão ambiental e 9 sobre a dimensão ecológica) em uma equação torna inviável a estimação dos parâmetros por causa do alto grau de multicolinearidade. Portanto, uma solução para o problema sem perda significativa de informação e do poder explicativo do conjunto de variáveis é dada por meio da elaboração de indicadores por meio da técnica de análise fatorial.

É com este propósito que o trabalho contribui para a especificação dos modelos econométricos e, sobretudo, para os métodos utilizados na estimação dos parâmetros das regressões múltiplas.

\subsection{Indicadores ambiental e ecológico da Flona de Carajás}

Os resultados da análise fatorial estão reunidos nas Tabelas 1 e 2 . As duas matrizes de correlação apresentaram determinantes diferentes de zero, logo admitem inversa e a solução resultante além de única é a que melhor representa o fenômeno (DILLON; GOLDSTEIN, 1984; JOHNSON; WICHERN, 2007; SANTANA et al., 2014; FERREIRA et al., 2016). De acordo com os testes KMO de 0,588 e 0,76 (superior ao limite aceitável de 0,50) e os testes de esfericidade de Bartlett significativos a 1\%, a amostra adequase à análise fatorial. As cargas fatoriais estimadas apresentaram significância a 1\%, confirmando a adequação dos modelos. Todas as comunalidades situaram-se acima de 0,50, o que valida suas participações na definição dos fatores latentes (JOHNSON; WICHERN, 2007; HAIR JR et al., 2009). Por fim, os fatores extraídos nos dois modelos fatoriais explicaram mais de $60 \%$ da variância total dos dados (DILLON; GOLDSTEIN, 1984; SANTANA, 2007). Sendo assim, considera-se que o modelo foi bem especificado e os resultados revelam a realidade do fenômeno estudado.

\subsubsection{Fatores definidores da dimensão ambiental}

O modelo de análise fatorial especificado para refletir o comportamento da dimensão ambiental foi configurado por cinco fatores e explicou $71,88 \%$ da variância total dos dados (Tabela 1). O primeiro fator explicou $18,4 \%$ da variância e representa a força conjunta de duas variáveis que, na percepção dos entrevistados, refletem a redução do uso do fogo na implantação de atividades agrícolas e no manejo de pastagens. Por isso, pode ser nominada queimadas. Esta dimensão é a mais importante, dado que o fogo destrói a biodiversidade da área e compromete todas as funções dos serviços ecossistêmicos. Além disso, por estar localizada no espaço definido como "arco do desmatamento", a área vem recebendo tratamento diferenciado quanto à eficácia da atuação dos órgãos ambientais, tendo em vista o controle preventivo do desmatamento e queimadas.

O segundo fator explicou $15,36 \%$ da variância comum e representa o efeito das variáveis conscientização ambiental e preservação da biodiversidade da Flona de Carajás. Em função da maior carga fatorial da segunda variável, a dimensão pode ser chamada de biodiversidade. Este fator está relacionado com a eficácia da política ambiental no combate aos efeitos produzidos pelo desmatamento, queimadas, extração mineral e a atuação no processo de conscientização das pessoas para preservarem a biodiversidade.

Tabela 1. Matriz de cargas fatoriais do modelo representativo das condições ambientais da Floresta Nacional de Carajás, estado do Pará, 2014. Table 1. Matrix of factorial loads of therepresentativemodel of theenvironmentalconditionsof the Carajás NationalForest, state of Pará, 2014.

\begin{tabular}{lrrrrrc}
\hline Variáveis & Fator 1 & Fator 2 & Fator 3 & Fator 4 & Fator 5 & Comunalidade \\
\hline Redução da queima em roça & 0,937 & 0,143 & 0,05 & 0,089 & 0,006 & 0,909 \\
Redução da queima em pasto & 0,941 & 0,118 & 0,074 & 0,071 & 0,021 & 0,91 \\
Preservação da biodiversidade & 0,077 & 0,853 & 0,027 & $-0,054$ & 0,076 & 0,743 \\
Aumento da consciência ambiental & 0,167 & 0,839 & $-0,006$ & 0,081 & $-0,032$ & 0,739 \\
Aumento da poluição dos rios & 0,011 & $-0,029$ & 0,821 & 0,072 & 0,064 & 0,685 \\
Redução de peixe dos rios & 0,1 & 0,05 & 0,775 & 0,074 & $-0,137$ & 0,637 \\
Redução da extração de PFNM & $-0,021$ & $-0,044$ & 0,043 & 0,816 & $-0,094$ & 0,679 \\
Redução da extração de PFM & 0,177 & 0,071 & 0,108 & 0,76 & 0,07 & 0,63 \\
Aumento de irregularidade chuvas & $-0,042$ & 0,151 & 0,201 & 0,196 & $-0,695$ & 0,587 \\
Aumento de turistas na área & $-0,015$ & 0,194 & 0,107 & 0,147 & 0,773 & 0,669 \\
\hline Soma de quadrado das cargas & 1,841 & 1,536 & 1,349 & 1,337 & 1,125 & 7,188 \\
Percentual do traço (\%) & 18,407 & 15,364 & 13,492 & 13,368 & 11,252 & 71,883 \\
Adequação da amostra: KMO $=0,588$ & & & Batlett'stest $=899,577(\mathrm{vp}<1 \%)$ & & \\
\hline
\end{tabular}

Fonte: Dados da pesquisa.

O terceiro fator, que explicou $13,49 \%$ da variância dos dados, está associado às variáveis poluição das águas e redução do estoque de peixes dos rios e igarapés. Neste caso, o fator pode ser denominado de poluição das águas. Esta poluição está associada ao desmatamento da floresta para a implantação das atividades agropecuárias e ao processo desordenado da urbanização das cidades e vilas, como reflexo dos projetos de extração do minério de ferro. Assim, a redução do estoque de peixes e da qualidade da água via assoreamento dos rios e poluição com produtos químicos, descargas de esgoto e lixo, foi captada neste fator, que influencia as pessoas nas decisões de preservar e/ou de utilizar racionalmente este 
recurso natural. Este fator tem efeito direto na alimentação e saúde da população local.

O quarto fator explicou $13,37 \%$ da variância dos dados e capta os efeitos das variáveis extração de produtos madeireiros e não madeireiros da Flona de Carajás e pode ser denominado de extrativismo vegetal. Este fator representa o efeito da atuação dos órgãos ambientais no controle da extração predatória dos recursos florestais madeireiros e não madeireiros. O quinto fator explicou $11,25 \%$ da variância total dos dados e representa as variáveis aumento na irregularidade das chuvas e da frequência de turistas na região. Estas variáveis apresentaram efeitos opostos na definição do fator, pois a diminuição da irregularidade do clima pode favorecer as belezas naturais da Flona de Carajás e aumentar o turismo ecológico. Por outro lado, a irregularidade das chuvas, com secas prolongadas e temperaturas elevadas tem aumentado as queimadas espontâneas das áreas de savana e de pastagens, prejudicando o turismo ecológico e pondo em risco a biodiversidade. Esta dimensão pode ser denominada de potencial turístico. O efeito combinado deste conjunto de fatores configura a dimensão ambiental, cujo comportamento influencia diretamente o bem-estar da população local.

\subsubsection{Fatores definidores da dimensão ecológica}

A dimensão ecológica foi configurada por três fatores (Tabela 2). O primeiro fator explicou 25,6\% da variância total dos dados e representa o efeito de quatro variáveis descritoras do potencial dos serviços ecossistêmicos: nascentes e rios com água potável; belezas naturais (fontes d'água, cachoeiras e paisagens florísticas); espécies raras e endêmicas (flor de Carajás, gavião real); e a bacia hidrográfica que contribui para manter o fluxo de água de rios e igarapés e para regular o clima local e regional. Este fator engloba as funções de provisão, cultural, espiritual e de conhecimento, que expressam o valor de uso e o valor de não uso desse ativo natural, podendo ser chamado de serviço ambiental.

O segundo fator explicou $23,4 \%$ da variância e capta os efeitos de três variáveis que indicam o potencial dos produtos madeireiros e não madeireiros e dos animais silvestres da Flona de Carajás. Assim, o fator representa a função provimento de produtos com valor comercial e pode ser denominado de potencial ecológico e econômico. A madeira e os animais silvestres de caça têm valor monetário nos mercados formal e informal. Embora a caça seja proibida para fins comerciais, é praticada para o autoconsumo. O excedente é comercializado com preço acima do equilíbrio do mercado, para compensar o risco da apreensão do produto, juntamente com a aplicação de multas e demais sanções para o infrator.

Tabela 2. Matriz de cargas fatoriais do modelo representativo do potencial multifuncional do ativo ambiental da Floresta Nacional de Carajás, estado do Pará, 2014.

Table 2. Matrix of fatorial loads of representative model of multifunctional potential of the environmental atractives of the Carajás NationalForest, state of Pará, 2014.

\begin{tabular}{lcccc}
\hline Variáveis & Fator 1 & Fator 2 & Fator 3 & Comunalidade \\
\hline Fontes de água potável & 0,73 & 0,198 & 0,003 & 0,573 \\
Áreas de potencial turístico & 0,706 & 0,247 & 0,059 & 0,563 \\
Espécies raras e endêmicas & 0,704 & 0,121 & 0,145 & 0,531 \\
Bacia para regular clima & 0,771 & 0,116 & 0,029 & 0,608 \\
Flona rica em madeiras & 0,103 & 0,864 & 0,172 & 0,787 \\
Flona rica em produto não madeireiro & 0,306 & 0,731 & $-0,038$ & 0,629 \\
Flona rica em animais silvestres & 0,212 & 0,803 & 0,106 & 0,701 \\
Terra com aptidão para pasto & $-0,014$ & 0,067 & 0,916 & 0,843 \\
Terra com aptidão para agricultura & 0,182 & 0,121 & 0,881 & 0,825 \\
\hline Soma de quadrado das cargas & 2,304 & 2,074 & 1,683 & 6,061 \\
Percentual do traço (\%) & 25,6 & 23,046 & 18,698 & 67,344 \\
Adequação da amostra: KMO $=0,760$ & & Batlett'stest $=1245,153(\mathrm{vp}<1 \%)$ & & \\
\hline
\end{tabular}
Fonte: Dados da pesquisa.

O terceiro fator, que explicou $18,7 \%$ da variância total dos dados, está associado às variáveis que definem o potencial das terras para o desenvolvimento de pastagens em uso na pecuária e de atividades agrícolas. Neste caso, o fator representa a função de suporte do solo para o desenvolvimento sustentável de atividades econômicas e pode ser denominado de potencial agropecuário. Este fator reflete o efeito do mercado de terras na área do entorno da Flona de Carajás, tanto em transações de compra e venda de terras para fins agropecuários, quanto para efeito de indenização das áreas de abrangência dos projetos de mineração, de assentamento da reforma agrária, ou para efeito de preservação ambiental. A interação destes fatores gera a dimensão ecológica e explica, na percepção do entrevistado, sua importância para o bemestar da população.

4.3.3 Indicadores das dimensões ambiental e ecológica

$\mathrm{O}$ indicador do potencial ecológico da Flona de Carajás contemplou o conjunto da multifuncionalidade dos produtos e serviços ecossistêmicos e foi declarado por $52,0 \%$ dos entrevistados como de alta importância, sendo 18,6\% classificados como de significância muito alta (Tabela 3). Uma parcela de $33,5 \%$ dos entrevistados declarou que esse potencial é intermediário e apenas $15,2 \%$ o considerou como baixo.

Estes resultados representam a interação dos fatores considerados nas análises da Economia Ambiental, que admite a combinação do uso do capital natural com o capital fabricado em proporção não fixas ao admitir graus diferenciados de substituição na geração de outros produtos e serviços, com as análises da Economia Ecológica que consideram o uso dos ativos naturais e fabricados em proporção relativamente fixas, admitindo substituição apenas no limite (SANTANA, 2015; SANTANA et al., 2017a). Esta premissa torna-se ainda mais definida na medida em que o uso dos recursos naturais se aproxima dos níveis mínimos de seus estoques e/ou de suas capacidades de resiliência (SANTANA et al., 2016; 2017b). 
Além disso, o indicador evidencia a percepção do entrevistado sobre a importância da Flona de Carajás pelo potencial econômico e ambiental do capital natural que conta com as espécies raras e/ou endêmicas e que não são destinadas ao uso. Este é um forte indicador do grau de percepção da população entre as mudanças nos serviços ecossistêmicos e sua influência no bem-estar social.

Tabela 3. Indicadores de fluxo de recursos para uso direto e indireto e de não uso pela sociedade, da Floresta Nacional de Carajás, estado do Pará, 2014.

Table 3. Indicators of resurce fluxes for the direct and indirect use and non-use by society, Carajás National Forest, state of Pará, 2014.

\begin{tabular}{lcccc}
\hline \multicolumn{1}{c}{ Intervalo do indicador } & Dimensão Ecológica & Percentual (\%) & Dimensão Ambiental & Percentual (\%) \\
\hline Valor maior ou igual a 0,8 & 82 & 18,55 & 62 & 14,03 \\
Valor de 0,6 a 0,79 & 148 & 33,48 & 187 & 42,31 \\
Valor de 0,4 a 0,59 & 145 & 32,81 & 141 & 31,90 \\
Valor inferior a 0,4 & 67 & 15,16 & 52 & 11,76 \\
\hline Amostra total & 442 & 100 & 442 & 100 \\
\hline
\end{tabular}

Fonte: Dados da pesquisa.

O indicador da dimensão ambiental, que incorpora os fatores representativos da sustentabilidade do capital natural da Flona de Carajás, foi classificado por $56,3 \%$ dos entrevistados como de alto grau, sendo que 14,0\% o consideraram de importância muito alta. Outros 31,9\% classificaram o indicador no valor intermediário e apenas $11,8 \%$ observaram que os efeitos ambientais são de baixa relevância. Este grau de reconhecimento permite afirmar que a dimensão ambiental é fundamental para determinar as condições de bem-estar da população e, por isso, deve compor o valor econômico total da Flona de Carajás. Dessa forma, a população pode decidir pela preservação, com base na disposição a pagar ou explorar o recurso, manifestando sua disposição a receber uma indenização para compensar a perda do ativo e viabilizar a extração do minério de ferro e de outras atividades econômicas.

Portanto, o grande número de variáveis categóricas deve ser substituído por estes indicadores das componentes ambiental e ecológica em modelos econométricos no âmbito da avaliação contingente (SANTANA, 2014; SANTANA et al., 2017b), juntamente com as demais variáveis econômicas e sociodemográficas. Desta forma, pode-se captar o efeito destas componentes no valor econômico total dos ativos naturais.

\section{CONSIDERAÇÕES FINAIS}

A pesquisa de campo foi validada pelo amplo esclarecimento aos entrevistados sobre a importância dos serviços ambientais produzidos pela Flona de Carajás e sua contribuição para a qualidade de vida das pessoas e para compor o valor econômico total da Amazônia. Neste aspecto, $76,9 \%$ dos entrevistados afirmaram que conheciam os ecossistemas de floresta densa e de savana metalófita e mais de $80 \%$ afirmaram ter conhecimento sobre a importância econômica e ambiental da Flona de Carajás, dos efeitos das mudanças climáticas e da ação antrópica na região.

A revelação dos entrevistados sobre o valor do potencial econômico e ambiental dos produtos e serviços produzidos pelos ecossistemas de floresta e savana da Flona de Carajás situou-se acima de $80 \%$ para a maioria das variáveis descritoras da dimensão ecológica.

A importância dos indicadores das componentes ambientais e ecológicas para definir um valor econômico para garantir a preservação ou compensar a supressão da Flona de Carajás foram considerados como de alta importância por mais de $52 \%$ dos entrevistados. Portanto, a população local indicou ter percepção sobre os efeitos das mudanças ambientais produzidas pela ação antrópica sobre os recursos naturais e as consequências sobre o desempenho da economia e a qualidade de vida das pessoas.

\section{REFERÊNCIAS}

ADAMS, C.; MOTTA, R. S.; ORTIZ, R. A.; REID, J.; AZNAR, C. E.; SINISGALLI, P. A. A. The use of contingent valuation for evaluating protected areas in the developing world: economic valuation of Morro do Diabo State Park, Atlantic Rainforest, São Paulo State (Brazil). Ecological Economics, v. 66, n. 2, p. 359-370, 2008. DOI: https://dx.doi.org/10.1016/j.ecolecon.2007.09.008

BARAL, N.; STERN, M. J.; BHATTARAI, R. Contingent valuation of ecotourism in Annapurna conservation area, Nepal: implications for sustainable park finance and local development. Ecological Economics, Amsterdam, v. 66, n. 2, p. 218-227, 2008. DOI: https://dx.doi.org/10.1016/j.ecolecon.2008.02.004

BENTES, E. S.; SANTANA, A. C.; HOMMA, A. K. O.; GOMES, S. C. Valoração econômica da jusante da barragem de Tucuruí. Revista de Política Agrícola, Brasília, v. 23, n. 4, p. 102-110, 2014.

CAMPOS, J. C.; CASTILHO, A. F. Uma visão geográfica da região da Flona de Carajás. In: MARTINS, F. D.; CASTILHO, A. F.; CAMPOS, J.; HATANO, F. M.; ROLIM, S. G. (Org.). Fauna da Floresta Nacional de Carajás: estudos sobre vertebrados terrestres. São Paulo: Nitro Images, 2012. p. 16-63.

CARSON, R.T. Contingent valuation: a practical alternative when prices aren't available. Journal of Economic Perspectives, v.26, n.1, p.27-42, 2012. http://dx.doi.org/10.1257/jep.26.4.27.

CARSON, R. T.; LOUVIERE, J. A common nomenclature for stated preference elicitation approaches. Environmental and Resource Economics, v. 49, n. 4, p. 539-559, 2011. DOI: https://dx.doi.org/10.1007/s10640-010-9450-x

COSTANZA, R.; D’ARGE, R; GROOT, R. de; FARBER, S.; GRASSO, M.; HANNON, B.; LIMBURG, K.; NAEEM, S.; O'NEILL, R. V.; PARUEDO, J.; RASKIN, R.G.; SUTTON, P.; VAN DEN BELT, M. The value of the world's ecosystem services and natural capital. Nature, v. 15, n. 2, p. 253-260, 1997. DOI: https://dx.doi.org/10.1038/387253a0

COSTANZA, R.; GROOT, R. de; SUTTON, P.; PLOEG, S.; ANDERSON, S. J.; KUBISZEWSKI, I.; FARBER, S.; TURNER, R. K. Changes in the global value of ecosystem services. Global Environmental Change, Guildford, v. 
26, n. 1, p. 152-158, 2014. DOI: https://dx.doi.org/10.1016/j.gloenvcha.2014.04.002

COSTANZA, R.; DALY, H. E. Natural Capital and Sustainable Development. Conservation Biology, Boston, v. 6 , n. 1 , p. 37-46, 1992. DOI: https://dx.doi.org/10.1046/j.1523-1739.1992.610037.x

DILLON, W. R.; GOLDSTEIN, M. Multivariate analysis: methods and applications. New York: John Wiley \& Sons, 1984. 587p.

FERREIRA, V. A.; SANTANA, A. C.; RAVENA, N.; OLIVEIRA, C. M. Os fatores de repercussão da cadeia produtiva do dendê no desenvolvimento local do Baixo Tocantins. Desenvolvimento e Meio Ambiente, Curitiba, v. $39, \quad$ p. 173-188, 2016. DOI: http://dx.doi.org/10.5380/dma.v39i0.46128.

FISHER, A. C.; KRUTILlA, J. V.; CICCHETH, C. J. The economics of environmental preservation: a theoretical and empirical analysis. The American Economic Review, Nashville, v. 42, n. 4, p. 605-619, 1972.

GROOT, R. de; BRANDER, L.; PLOEG, S.; COSTANZA, R.; BERNARD, F.; BRAAT, L; CHRISTIE, M.; CROSSMAN, N.; GHERMANDI, A.; HEIN, L.; HUSSAIN, S.; KUMAR, P.; MCVITTIE, A.; PORTELA, R.; RODRIGUEZ, L. C.; BRINK P. ten; BEUKERING, P. van. Global estimates of the value of ecosystems and their services in monetary units. Ecosystem Services, v. 1, n. 1, p. 50-61, 2012. DOI: https://dx.doi.org/10.1016/j.ecoser.2012.07.005

HAIR JR, J. F.; ANDERSON, R. E.; TATHAM, R. L.; BLACK, W. C. Análise multivariada de dados. Porto Alegre: Bookman, 2009. 688p.

HANEMANN, W. M. Valuing the environment through contingent valuation. Journal of Economic Perspectives, Nashville, v. 8, n. 4, p. 19-43, 1994. DOI: https://dx.doi.org/10.1257/jep.8.4.19

HOEHN, J. P.; RANDALL, A. A satisfactory benefit cost indicator from contingent valuation. Journal of Environmental Economics and Management, New York, v. 14, n. 2, p. 222-247, 1987. DOI: https://doi.org/10.1016/0095-0696(87)90018-0

JOHNSON, R. A.; WICHERN, D. W. Applied multivariate statistical analysis. New Jersey: Prentice-Hall, 2007. $773 \mathrm{p}$.

LIU, S.; COSTANZA, R.; FARBER, S.; TROY, A. Valuing ecosystem services: theory, practice, and the need for a transdisciplinary synthesis. Ecological Economics Reviews, v. 1185 , n. 1, p. 54-78, 2010. DOI: https://dx.doi.org/10.1111/j.1749-6632.2009.05167.x

LOOMIS, J.; KENT, P.; STRANGE, L.; FAUSCH, K.; COVICH, A. Measuring the total economic value of restoring ecosystem services in an impaired river basin: results from a contingent valuation survey. Ecological Economics, Amsterdam, v. 33, n. 1, p. 103-117, 2000. DOI: https://doi.org/10.1016/S0921-8009(99)00131-7

ROSA, A. G.; SANTANA, A. C.; OLIVEIRA, C. M.; SANTANA, Á. L. Valoração contingente da reserva extrativista de marinha Caeté-Taperaçu, Bragança, estado do Pará -Brasil. Espacios, v. 37, n. 9, p. 1-13, 2016.

SANTANA, A. C. Índice de desempenho competitivo das empresas de polpa de frutas do Estado do Pará. Revista de Economia e Sociologia Rural, Brasília, v. 45, n. 4, p. 749775, 2007. DOI: http://dx.doi.org/10.1590/S010320032007000300009
SANTANA, A. C.; SANTANA, Ádamo L.; SANTOS, M. A. S. Influência do desmatamento no mercado de madeira em tora da região Mamuru-Arapiuns, Sudoeste do Pará. Revista de Ciências Agrárias, v. 54, n. 1, p. 44-53, 2011.

SANTANA, A. C. Valoração ambiental da área de savana metalófita, ou canga, da Flona de Carajás para fins de indenização. Belém: UFRA/FUNPEA/VALE, 2014. 89p.

SANTANA, A. C.; SANTANA, A. L.; SANTANA, A. L.; COSTA, N. L.; NOGUEIRA, A. K. M. Planejamento Estratégico de uma Universidade Federal da Amazônia. Revista de Estudos Sociais, v. 32, n. 2, p. 183-204, 2014. DOI: http://dx.doi.org/10.19093/res.v16i32.2137

SANTANA, A. C. Valoração de produtos florestais não madeireiros da Amazônia: o caso da castanha-do-brasil. 103f. Tese (Doutorado em Ciências Florestais) Universidade Federal Rural da Amazônia. Belém, 2015.

SANTANA, A. C.; SANTANA, Á. L.; SANTANA, A. L.; GOMES, S. C.; SALOMÃO, R. P. Valoração dos danos ambientais causados por hidrelétricas para a produção de energia na bacia do Tapajós. Reflexões Econômicas, Ilhéus, v. 1, n. 1, p. 31-48, 2015.

SANTANA, A. C.; SANTANA, Á. L; SALOMÃO, R. P.; SANTANA, Á. L.; COSTA, N. L.; SANTOS, M. A. S. O custo socioambiental da destruição de castanheiras (Bertholletia excelsa) no estado do Pará. Revista de Estudos Sociais, Cuiabá, v. 37, n. 2, p. 3-21, 2016. DOI: http://dx.doi.org/10.19093/res.v18i37.2997

SANTANA, A. C.; SALOMÃO, R. P.; SANTANA, Á. L.; CASTILHO, A.; GOMES, S. C. O valor econômico da savana metalófita da Floresta Nacional de Carajás, estado do Pará: uma contribuição teórica e metodológica. Teoria e Evidência Econômica, v. 23, p. 9-38, 2017a. DOI: http://dx.doi.org/10.5335/rtee.v23i48.7358

SANTANA, A. C.; SANTANA, Á. L.; AMIN, M. M.; SALOMÃO, R. P.; COSTA, N. L.; SANTOS, M. A. S.; CASTILHO, A. F. Theoretical and methodological contributions to the contingent evaluation of the natural resources of the Carajás National Forest. International Journal of Development Research, v. 7, n. 4, p. 1246812474, 2017b.

SUTTON, P. C.; COSTANZA, R. Global estimates of market and non-market values derived from nighttime satellite imagery, land cover, and ecosystem service valuation. Ecological Economics, Amsterdam, v. 41, n. 3, p. 509527, 2002. DOI: https://dx.doi.org/10.1016/S09218009(02)00097-6

TURNER, R. K.; PAAVOLA, J.; COOPER, P.; FARBER, S.; JESSAMY, V.; GEORGIOU, S. Valuing nature: lessons learned and future research directions. Ecological Economics, Amsterdam, v. 46, n. 2, p.493-510, 2003. DOI: https://dx.doi.org/10.1016/S0921-8009(03)00189-7

VERONESI, M.; CHAWLA, F.; MAURER, M.; LIENERT, J. Climate change and the willingness to pay to reduce ecological and health risks from wastewater flooding in urban centers and the environment. Ecological Economics, Amsterdam, v. 98, n. 1, p. 1-10, 2014. DOI: http://dx.doi.org/10.1016/j.ecolecon.2013.12.005

WALLACE, K. J. Classification of ecosystem services: problems and solutions. Biological Conservation, v. 139, n. $3-4, \quad$ p. 235-246, 2007. DOI: https://dx.doi.org/10.1016/j.biocon.2007.07.015 